\title{
JOB SATISFACTION, OCCUPATIONAL STRESS, BURNOUT AND WORK ENGAGEMENT AS COMPONENTS OF WORK-RELATED WELLBEING
}

\author{
SEBASTIAAN ROTHMANN \\ Programme in Industrial Psychology \\ North-West University \\ South Africa \\ Correspondence to: Sebastiaan Rothmann \\ e-mail: ian@ianrothmann.com
}

\begin{abstract}
The objective of this study was to investigate the relationship between job satisfaction, occupational stress, burnout and work engagement as dimensions of work-related wellbeing in a sample of members of the police force in South Africa. A survey design was used. Stratified random samples of members of the police force $(N=677)$ were taken in the North West Province of South Africa. The Minnesota Job Satisfaction Questionnaire, Police Stress Inventory, Maslach Burnout Inventory - General Survey and Utrecht Work Engagement Scale were used as measuring instruments. The results provided support for a four-factorial model of work-related wellbeing consisting of the following dimensions: job satisfaction (indicating pleasure vs. displeasure), occupational stress (indicating anxiety vs. comfort), burnout (indicating fatigue vs. vigour), and engagement (indicating enthusiasm vs. depression).
\end{abstract}

Keywords: wellness, motivation, energy, distress, eustress

Issues of employee wellbeing have never been more important than now (Cropanzano \& Wright, 2001). Research related to the happiness of employees is necessary, not only because of the happy-productive worker thesis, but also because of claims that many people are unhappy (Myers \& Diener, 1997). Subjective wellbeing is an important indicator of the wellbeing of individuals (Kahn \& Juster, 2002). Wellbeing could be considered in terms of different life roles, such as marriage, family, work and housing. Work represents an important context for studying the wellbeing of individuals, especially because it provides a source of income that impacts on various life roles, and because it demands a significant part of individuals' time and energy. Work also ranks high among the determinants of life satisfaction.

Unfortunately, work-related wellbeing has often been narrowly operationalised as job satisfaction. As a result, Daniels (2000) suggested that affective wellbeing is assessed. Affective wellbeing is regarded as multidimensional and could capture subtleties in experiences of work. Job satisfaction, occupational stress, burnout and work engagement are important dimensions of the affective work-related wellbeing of employees (Cropanzano \& Wright, 2001).

The police service in South Africa presents an interesting context for studying the relationship between job satisfaction, occupational stress, burnout and work engagement. Police work has been identified as a stressful occupation (Alexander, 1999; Anshel, 2000). This is particularly true for South African circumstances, where high levels of crime and violence are prevalent (Pienaar \& Rothmann, 2003). Studies have been conducted regarding the job satisfaction, occupational stress, burnout and work engagement of police officers (e.g. Mostert \& Rothmann, 2006; Rothmann, Steyn \& Mostert, 2005). In addition to experiencing job-related stressors such as dealing with the unlawful, often dangerous, actions of citizens, there are factors such as abusive treatment in the workplace, organisational inefficiency and a general lack of social and managerial support (Koortzen, 1996). Decreased levels of wellbeing compared to norms for the general population are found in research on members of the police force (Pienaar, Rothmann \& Van de Vijver, 2007; Rothmann \& Strijdom, 2002).

No studies regarding the relationships between the different dimensions of work-related wellbeing (including job satisfaction, occupational stress, burnout and work engagement) of members of the police force in South Africa were found. When measuring the work-related wellbeing of police officers (e.g. in diagnostic studies), it is necessary to know whether dimensions such as occupational stress, job satisfaction, burnout and work engagement form part of an overall dimension, or whether they are independent but related dimensions. Multidimensional approaches can contribute to our understanding of the nature, causes and consequences of work-related wellbeing.

The objective of this study was to investigate the relationship between various dimensions of work-related wellbeing, namely job satisfaction, occupational stress, burnout and work engagement.

\section{Dimensions of work-related wellbeing}

Warr (2002) focused on wellbeing in the work context. Warr (2002, p. 2-3) suggested a model which can be used to examine workrelated wellbeing along three dimensions, namely pleasuredispleasure, anxiety-comfort, and enthusiasm-depression. Pleasure-displeasure refers to a person's level of job satisfaction (or life satisfaction in a more general sense). On the anxietycomfort dimension, feelings of anxiety are a result of low pleasure and high mental arousal, whereas comfort is a result of low arousal and pleasure. On the enthusiasm-depression dimension, depression indicates low pleasure and low mental arousal, whereas enthusiasm indicates high pleasure and high mental arousal. Warr (2002) also mentioned the possibility of a fourth dimension, namely fatigue-vigour. Many current instruments for measuring work-related wellbeing (e.g. job satisfaction, occupational stress, burnout and work engagement) tap the affective dimension of wellbeing.

Pleasure-displeasure dimension. Job satisfaction forms part of the pleasure-displeasure dimension of work-related wellbeing. According to Warr (2002), work-related wellbeing was traditionally studied in terms of employees' satisfaction with their jobs. Job satisfaction is the extent to which people like their jobs (Hirschfeld, 2000). Cranny, Smith and Stone (1992) point out that job satisfaction is a reaction to a job, which stems from the incumbent's comparison of actual outcomes with expected outcomes.

Job satisfaction has been conceptualised and operationalised as both a global and a multidimensional construct. On a global 
level, job satisfaction is considered in terms of an employee's overall satisfaction with his or her job. As a multidimensional construct, job satisfaction concerns satisfaction with pay, supervision, company policy and the nature of the work. Job satisfaction consists of an extrinsic and intrinsic component. Intrinsic job satisfaction is how people feel about the nature of the job tasks themselves, while extrinsic job satisfaction is how people feel about aspects of the work situation that are external to the job tasks (Hirschfeld, 2000).

Anxiety-comfort dimension. Feelings of anxiety combine low pleasure with high mental arousal, while feelings of comfort combine low arousal with pleasure (Warr, 2007). The combination of low pleasure with high mental arousal is indicative of stress. Individuals low- high on comfort (i.e. they experience low arousal and high pleasure) may have limited commitment, energy and aspirations.

Occupational stress is defined as a disruption of the equilibrium of the cognitive-emotional-environmental system by external factors (Lazarus \& Folkman, 1984). Stress is conceptualised as a complex process that consists of three major components, namely a) sources of stress that are encountered in the work environment, b) perception and appraisal of a particular stressor by an employee, and c) the emotional reactions that are evoked when a stressor is appraised as threatening (Lazarus, 1991; Spielberger, Vagg \& Wasala, 2003). The appraisal of a stressor as threatening leads to the emotional arousal of anxiety and the associated activation of the autonomic nervous system. If severe and persistent, the resulting physical and psychological strain may cause adverse behavioural consequences (Spielberger et al., 2003). According to Brooks and Piquero (1998) and Pienaar and Rothmann (2003), research supports the notion that occupational stress stems from two sources, namely job demands and a lack of job resources.

Vigour-fatigue dimension. Burnout forms part of the vigourfatigue dimension. Exhaustion represents the vigour-fatigue dimension because it refers to feelings of being overextended and depleted of one's emotional resources (Van Horn, Taris, Schaufeli \& Schreurs, 2004). Schaufeli and Enzmann (1998, p. 36) define burnout as "a persistent, negative, workrelated state of mind in 'normal' individuals that is primarily characterised by exhaustion, which is accompanied by distress, a sense of reduced effectiveness, decreased motivation, and the development of dysfunctional attitudes and behaviours at work." According to Maslach, Schaufeli and Leiter (2001), burnout is a syndrome consisting of three dimensions, namely exhaustion, cynicism and reduced professional efficacy. Exhaustion refers to feelings of reduction in the emotional resources of an employee. Cynicism refers to a negative, cynical and insensitive attitude towards work. Reduced professional efficacy refers to feelings of insufficiency, incompetence, lack of achievement and underproductiveness. However, Schaufeli (2003) recently questioned the inclusion of professional efficacy as a component of burnout. It was argued that professional efficacy is a trait that could contribute to burnout, rather than being a component of burnout.

Enthusiasm-depression dimension. Feelings of depression combine low pleasure with low mental arousal, while feelings of enthusiasm combine pleasure with high mental arousal. Feelings of enthusiasm indicate learning and vitality.

Work engagement forms part of the enthusiasm-depression dimension. Work engagement is defined as a positive, fulfilling, work-related state of mind that is characterised by vigour, dedication and absorption. Furthermore, it is not a momentary and specific state, but a more persistent and pervasive affectivecognitive state that is not focused on a particular object, event, individual or behaviour (Schaufeli, Salanova, González-Romá \& Bakker, 2002). Vigour is characterised by high levels of energy and mental resilience while working, as well as a willingness to exert effort and to persist even through difficult times. Dedication is characterised by a sense of significance in one's work, feeling enthusiastic, inspired and proud, and by viewing work as a challenge. Absorption refers to an optimal state of experience where focused attention, a clear mind, effortless concentration, complete control, loss of self-consciousness, distortion of time and intrinsic enjoyment are experienced.

\section{The relationship between job satisfaction, occupational stress, burnout and work engagement}

The different components of work-related wellbeing could be related, but could also be separate dimensions (see Warr 2002). For example, it is possible to experience low work-related depression (e.g. disengagement), but high levels of workrelated anxiety (e.g. occupational stress). Strain results from the combination of two or more negative forms of wellbeing, such as anxiety (e.g. occupational stress) and depression (e.g. disengagement)

Regarding the relationship between occupational stress and work engagement, research has shown that even when exposed to high job demands and working long hours, some individuals do not show symptoms of disengagement. Instead, they seem to find pleasure in dealing with these stressors (Schaufeli \& Bakker, 2004). According to Terry, Nielson and Perchard (1993), high levels of stress are associated with low levels of job satisfaction (which represents the pleasure component of work-related wellbeing). Fairbrother and Warn (2003) confirm that occupational stress is negatively related to job satisfaction. Furthermore, it seems that job satisfaction has a protective effect on the relation between occupational stress and disengagement (Ramirez, Graham, Richards, Cull \& Gregory, 1996; Visser, Smets, Oort \& deHaes, 2003). Visser et al. (2003) confirm that job satisfaction has a protective effect against the negative consequences of occupational stress. They suggest that when stress is high and satisfaction is low, the risk of low energy - a central aspect of low work engagement - increases considerably.

Zedeck, Maslach, Mosier and Skitka (1988) conclude that burnout and job dissatisfaction are clearly linked. However, the nature of the link between burnout and job dissatisfaction is a matter of speculation. It is not clear whether burnout causes people to be dissatisfied with their jobs, or whether job dissatisfaction causes burnout. Also, burnout and job dissatisfaction may be caused by another factor, such as poor working conditions.

\section{RESEARCH DESIGN}

\section{Research approach}

A cross-sectional survey design was used.

\section{Participants}

The study population included members of the police force $(N=677)$ from police stations in the North-West Province. A total of $42 \%$ of the participants were male and $58 \%$ were female. The mean age of the participants was 35.76 years. Fifty-nine per cent of the participants were matriculants. Thirty-three per cent were single, while $56 \%$ were married and $7 \%$ were divorced.

\section{Measuring instruments}

The Minnesota Job Satisfaction Questionnaire (MSQ) (Weiss, Dawis, England \& Lofquist, 1967) indicates how satisfied or dissatisfied respondents are with their jobs by asking them to rate themselves on 20 questions by using a scale from 1 (very dissatisfied) to 5 (very satisfied). The revised MSQ short form measures intrinsic job satisfaction and extrinsic job satisfaction using statements like: "The chance to be 'somebody' in the community"; "The way my supervisor handles his/her workers", and "The praise I get for doing a good job". Hirschfeld (2000) found that a twofactor model (intrinsic and extrinsic job satisfaction) is superior 
to a one-factor model (total job satisfaction). Rothmann (2005) confirmed a two-factor model of job satisfaction, consisting of Intrinsic and Extrinsic Job Satisfaction, in a sample of South African Police Service (SAPS) members. Alpha coefficients for the two scales of the MSQ short form were 0,84 and 0,89 respectively (Rothmann, 2005).

The Police Stress Inventory (PSI) was used to measure the occupational stress of the participants. The PSI focuses on common work events that often result in psychological strain. The questionnaire consists of 28 stressful job-related events, focusing mainly on the amount of stress on a scale varying from 1 (low) to 9 (high). Pienaar and Rothmann (2003) subjected the PSI to a factor analysis on a sample of members of the police force and extracted two factors, namely Stress: Job Demands $(\boldsymbol{\alpha}=0,92)$, and Stress: Lack of Job Resources $(\boldsymbol{\alpha}=0,92)$.

The Maslach Burnout Inventory - General Survey (MBI-GS) (Maslach, Jackson \& Leiter, 1996) was used to measure burnout. The MBI-GS has three subscales: Exhaustion (five items; e.g. "I feel used up at the end of the workday"), Cynicism (five items, e.g. "I have become less enthusiastic about my work") and Professional Efficacy (six items, e.g. "In my opinion, I am good at my job"). Only two of the subscales, namely Exhaustion and Cynicism, were used for the purpose of this study. Internal consistencies (Cronbach alpha coefficients) reported by Maslach et al. (1996) varied from 0,87 to 0,89 for Exhaustion, and 0,73 to 0,84 for Cynicism. Test-retest reliabilities after one year were 0,65 (Exhaustion) and 0,60 (Cynicism) (Maslach et al., 1996). All items are scored on a seven-point frequency rating scale ranging from 0 (never) to 6 (daily). Storm (2002) confirmed the threefactor structure of the MBI-GS in a sample of SAPS members. However, Professional Efficacy (one of the subscales of the MBIGS) was not included in this study because it is regarded as a personality disposition rather than a wellness dimension. The following Cronbach alpha coefficients were obtained for the other two scales of the MBI-GS: Exhaustion: 0,88; Cynicism: 0,79 (Storm, 2002).

The Utrecht Work Engagement Scale (UWES) (Schaufeli et al., 2002) was used to measure work engagement. Two subscales of the UWES were used in this study, namely Vigour (six items; e.g. "I am bursting with energy in my work") and Dedication (five items; e.g. "I find my work full of meaning and purpose"). The Absorption scale of the UWES was not used in this study because of problems with the wording of the items (Rothmann, 2005). The UWES is scored on a seven-point frequency rating scale, varying from 0 (never) to 6 (always). Rothmann (2005) confirmed the two-factor structure of the UWES (consisting of Vigour and Dedication) in the SAPS. Storm and Rothmann (2003) obtained the following alpha coefficients for the UWES in a sample of members of the police force: Vigour: 0,78; Dedication: 0,89. In a sample of South African emergency workers, Naudé and Rothmann (2004) extracted one factor using exploratory factor analysis, namely Vigour/Dedication $(\alpha=0,87)$.

\section{Data analysis}

The data analysis was carried out with the SPSS 15.0 program (SPSS Inc., 2006) and the AMOS program (Arbuckle, 2006). First, descriptive statistics (e.g. means, standard deviations, skewness and kurtosis) were used to explore the data. Cronbach alpha coefficients ( $\alpha$ ) were used to assess the internal consistency of the measuring instruments (Clark \& Watson, 1995). Pearson product-moment correlation coefficients were used to specify the relationships between the variables. Structural equation modelling (SEM) methods, as implemented by AMOS (Arbuckle, 1997), were used to test the models of work-related wellbeing, using the maximum likelihood method. The Goodness-of-fit Index (GFI), Adjusted Goodness-of-Fit Index (AGFI), Normed Fit Index (NFI), Comparative Fit Index (CFI), Tucker-Lewis Index (TLI) and Root Mean Square Error of Approximation (RMSEA) were used.

\section{RESULTS}

\section{Descriptive statistics and correlations}

Descriptive statistics and Cronbach alpha coefficients of the PSI, MSQ, MBI-GS and UWES for police officers $(N=677)$ are reported in Table 1.

Table 1 shows that acceptable Cronbach alpha coefficients were obtained on all the dimensions of the MSQ, PSI, MBI-GS and UWES, varying from 0,74 to 0,91 (see Nunnally \& Bernstein, 1994).

The correlations between the MSQ, PSI, MBI-GS and UWES for police officers $(N=677)$ are reported in Table 2 .

Table 2 shows that Stress: Job Demands is statistically significantly related to Exhaustion and Cynicism $(p<0,01)$. Stress: Lack of Support is statistically significantly and positively related to Exhaustion and Cynicism, and negatively related to Vigour and Dedication $(p<0,01)$. Extrinsic and Intrinsic Job Satisfaction are statistically significantly related to Vigour and Dedication, and negatively related to Exhaustion and Cynicism $(p<0,01)$. Vigour and Dedication are statistically significantly negatively related to Exhaustion and Cynicism $(p<0,01)$.

\section{A structural model of work-related wellbeing}

Next, three models of work-related wellbeing were tested. First, a one-factor model, specifying that the four dimensions of work-related wellbeing form part of one factor (consisting of occupational stress, job satisfaction, burnout and work engagement), was tested. Second, a four-factor model specifying that work-related wellbeing consists of four separate, but related, dimensions, namely anxiety - comfort (i.e. occupational stress about job demands and a lack of resources); pleasure - displeasure (i.e. intrinsic extrinsic and intrinsic

TABLE 1

Descriptive statistics and cronbach alpha coefficients of the measuring instruments

\begin{tabular}{lccccc}
\hline TEST AND ITEMS & MEAN & SD & SKEWNESS & KURTOSIS & $\alpha$ \\
\hline PSI & & & & & \\
Job demands & 50.02 & 16.71 & -0.26 & -0.29 & 0.90 \\
Lack of resources & 93.95 & 27.91 & -0.20 & -0.12 & 0.91 \\
MSQ & & & & & \\
Extrinsic job satisfaction & 33.71 & 6.60 & -0.48 & 0.21 & 0.89 \\
Intrinsic job satisfaction & 34.56 & 9.77 & 0.02 & -0.44 & 0.84 \\
MBI-GS & & & & & \\
Exhaustion & 12.90 & 8.049 & 0.30 & -0.65 & 0.86 \\
Cynicism & 9.13 & 5.92 & 0.58 & -0.02 & 0.74 \\
UWES & & & & & \\
Vigour & 21.39 & 6.18 & -0.86 & 0.53 & 0.77 \\
Dedication & 23.98 & 6.15 & -1.37 & 1.53 & 0.85 \\
\hline
\end{tabular}

TABLE 2

Correlation coefficients between the PSI, MSQ, MBI-GS and UWES

\begin{tabular}{|c|c|c|c|c|c|c|c|}
\hline & 1 & 2 & 3 & 4 & 5 & 6 & 7 \\
\hline $\begin{array}{l}\text { 1. Stress: Job } \\
\text { demands }\end{array}$ & - & - & - & - & - & - & - \\
\hline $\begin{array}{l}\text { 2. Stress: Lack } \\
\text { of support }\end{array}$ & $0.72^{*}$ & - & - & - & - & - & - \\
\hline $\begin{array}{l}\text { 3. Extrinsic job } \\
\text { satisfaction }\end{array}$ & -0.07 & -0.08 & - & - & - & - & - \\
\hline $\begin{array}{l}\text { 4. Intrinsic job } \\
\text { satisfaction }\end{array}$ & 0.06 & 0.09 & $0.61^{*}$ & - & - & - & - \\
\hline 5. Exhaustion & $0.28^{*}$ & $0.24^{*}$ & $-0.36^{*}$ & $-0.25^{\star}$ & - & & - \\
\hline 6. Cynicism & $0.19^{\star \star}$ & $0.17^{\star}$ & $-0.19^{*}$ & $-0.24^{*}$ & $0.59^{*}$ & - & - \\
\hline 7. Vigour & -0.08 & $-0.13^{\star}$ & $0.20^{*}$ & $0.16^{*}$ & $-0.30^{*}$ & $-0.27^{*}$ & - \\
\hline 8. Dedication & -0.08 & $-0.15^{\star}$ & $0.21^{*}$ & $0.23^{*}$ & $-0.30^{*}$ & $-0.36^{*}$ & $0.78^{\star}$ \\
\hline
\end{tabular}

* Statistically significant $p \leq 0,01$ 
TABLE 3

Goodness-of-fit indices for three models of work-related wellbeing

\begin{tabular}{lcccccccc}
\hline \multicolumn{1}{c}{ MODEL } & $x^{2}$ & $x^{2} D F$ & GFI & AGFI & NFI & TLI & CFI & RMSEA \\
\hline $\begin{array}{l}\text { One-factor } \\
\text { model }\end{array}$ & 1446.25 & 72.31 & 0.65 & 0.37 & 0.30 & 0.31 & 0.30 & 0.33 \\
$\begin{array}{l}\text { Four-factor } \\
\text { model (1) }\end{array}$ & 390.62 & 27.90 & 0.88 & 0.67 & 0.81 & 0.63 & 0.82 & 0.20 \\
$\begin{array}{l}\text { Four-factor } \\
\text { model (2) }\end{array}$ & 80.12 & 5.34 & 0.97 & 0.93 & 0.96 & 0.97 & 0.97 & 0.08 \\
\hline
\end{tabular}

job satisfaction); enthusiasm - depression (i.e. dedication and cynicism), and fatigue - vigour (i.e. vigour and exhaustion), was tested. Third, a four-factor model specifying that work-related wellbeing consists of four separate, but related, dimensions, namely anxiety - comfort (i.e. occupational stress about job demands and a lack of resources); pleasure-displeasure (i.e. intrinsic extrinsic and intrinsic job satisfaction); enthusiasm - depression (i.e. vigour and dedication), and fatigue - vigour (i.e. exhaustion and cynicism) was tested. Table 3 shows the goodness-of-fit indices for the three models.

Table 3 shows that a four-factor model of work-related wellbeing fitted the data best $\left(x^{2}=80.12, x^{2} d f=5.34\right.$, GFI $=0.97$, AGFI $=0,93, \mathrm{NFI}=0,96, \mathrm{TLI}=0,97, \mathrm{CFI}=0,97, \mathrm{RMSEA}=0,08)$.

This model consists of four separate but related factors, namely occupational stress (indicating anxiety versus comfort at work), job satisfaction (indicating pleasure versus displeasure at work), burnout (indicating fatigue versus vigour at work), and work engagement (indicating enthusiasm versus depression at work). Figure 1 shows that burnout had a strong and negative loading on work-related wellbeing (a second-order factor). Occupational stress showed a moderate negative loading on work-related wellbeing, while work engagement and job satisfaction had moderate positive loadings. The signs of the regression coefficients were all in the expected direction.

\section{DISCUSSION}

This study investigated the job satisfaction, occupational stress, burnout and work engagement of police personnel, as well as the relationships between the constructs. The results provide support for a four-factorial model of workrelated wellbeing consisting of the following dimensions: job satisfaction (indicating pleasure vs. displeasure), occupational stress (indicating anxiety vs. comfort), burnout (indicating fatigue vs. vigour), and engagement (indicating enthusiasm vs. depression).

Occupational stress was statistically significantly related to exhaustion and cynicism in this study. This finding concurs with the results of Rothmann et al. (2005). Exhaustion (which refers to an incapability to perform) and cynicism (which refers to an unwillingness to perform) constitute the two key aspects of burnout (Schaufeli, 2003). In fact, cynicism - or psychological withdrawal from the task - can be seen as an adaptive mechanism to cope with excessive occupational stress and the resultant feelings of exhaustion. Occupational stress was not statistically significantly related to job satisfaction in this study. This finding is in contrast to that of Terry et al. (1993), and implies that employees could still like the extrinsic and intrinsic nature of their jobs (Hirschfeld, 2000), even when they experience high levels of occupational stress. The absence of a statistically significant relationship between occupational stress (because of job demands) and work engagement (vigour and dedication) is in line with the findings of Jackson, Rothmann and Van de Vijver (2006) and Schaufeli and Bakker (2004).

While occupational stress was not related to job satisfaction in this study, the results showed that both dimensions of burnout (i.e. exhaustion and cynicism) and work engagement (i.e. vigour

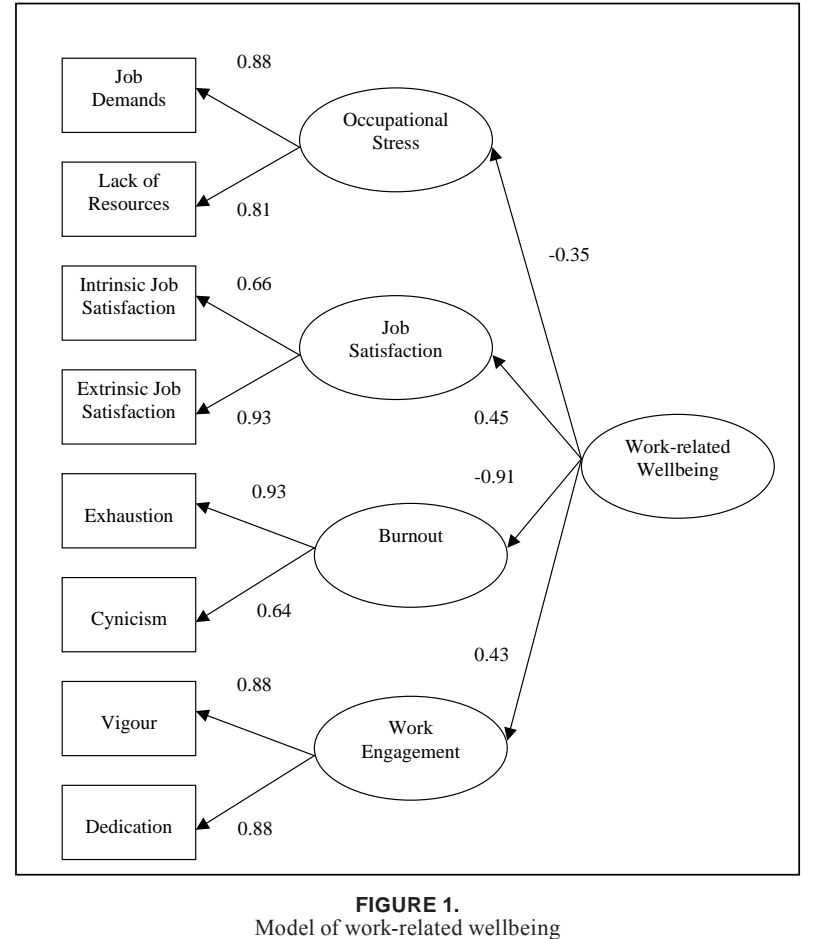

and dedication) were statistically significantly related to both dimensions of job satisfaction (i.e. intrinsic and extrinsic job satisfaction). However, with the exception of the relationship between extrinsic job satisfaction and exhaustion $(r=-0,36)$, the other relationships were of small practical significance $(r<0,30$; Cohen, 1988). It is clear that dissatisfaction with extrinsic aspects of the job is moderately related to employees' feelings of exhaustion. The nature of the link between burnout and job dissatisfaction is a matter of speculation. It is not clear whether burnout causes people to be dissatisfied with their jobs, or whether job dissatisfaction causes burnout (Zedeck et al., 1988). Also, burnout and job dissatisfaction may be caused by another factor, such as poor working conditions.

The results of this study confirm that work-related wellbeing is best represented by four separate but related factors, as described by Warr (2007). The first factor, namely occupational stress, indicates anxiety versus comfort at work. This factor is concerned primarily with personal threats, and with perceptions of danger leading to increased feelings of fear and tension. The second factor, namely job satisfaction, indicates pleasure versus displeasure at work. This factor represents feelings from bad to good about work. The third factor, namely burnout, indicates fatigue versus vigour at work. The last factor, namely work engagement, represents enthusiasm versus depression at work. The thoughts of depressed individuals revolve around loss and deprivation, which trigger deactivated feelings. Feelings ranging from depression to enthusiasm might be linked to a desire to move towards something that is wanted (Warr, 2007, p. 23).

It is clear from the results that work-related wellbeing entails more than just job satisfaction. In line with the argument of Daniels (2000), affective wellbeing is multidimensional. In this study, burnout (exhaustion and cynicism) had the highest loading $(-0.91)$ on the second order factor (i.e. Work-related Wellbeing), followed by job satisfaction (loading $=0.45$ ), work engagement (loading $=0.43$ ), and occupational stress (loading $=-0.35$ ). It seems that, within the police context, burnout is the strongest component of work-related wellbeing.

Exhaustion and vigour did not load on one factor (and thereby represent the dimension of fatigue versus vigour) as expected 
(Warr, 2002). Furthermore, cynicism and dedication also did not load together on one factor (representing the dimension of enthusiasm versus depression). Rather, two scales, namely vigour and dedication (which were measured by positivelyworded items only) formed one factor, while exhaustion and cynicism (which were measured by negatively-worded items), formed another factor. According to Kline (1994), the interpretation of factors from item content is not evidence of validity. A factor could load on items that have a particular format (in this study positive and negative item formats). A factor might also load on items that attract socially desirable responses or acquiescent responses, and such a factor would be a measure only of these response sets.

\section{RECOMMENDATIONS}

Based on the results of this study, it seems warranted to include all four dimensions described by Warr (2002), namely pleasuredispleasure, anxiety-comfort, enthusiasm-depression, and fatigue-vigour, when diagnosing the wellbeing of employees. It is recommended that managers in the police environment attend to the different components of affective work-related wellbeing as follows: first, regarding the pleasure-displeasure dimension of wellbeing, attention should also be paid to the factors that cause job dissatisfaction, such as working conditions, company policies, opportunities for advancement and the relation between pay and the amount of work. Second, regarding the anxiety-comfort dimension of wellbeing, occupational stressors such as too much paperwork, staff shortages, inadequate salary, seeing criminals go free, other officers not doing their job and inadequate or poor quality equipment should be measured. Third, regarding the vigour-fatigue dimension of wellbeing, exhaustion and cynicism should be measured. Fourth, regarding the enthusiasm-depression dimension of wellbeing, work engagement should be assessed.

Research regarding the causal relationships between job satisfaction, occupational stress, burnout and work engagement is also needed in other contexts. It is necessary to study these relationships in longitudinal studies. It might also be useful to include other constructs, such as ill health, job involvement and organisational commitment in these studies.

\section{Author Note}

This material is based on work supported by the National Research Foundation under Grant number 2053344.

\section{REFERENCES}

Anshel, M.H. (2000). A conceptual model and implications for coping with stressful events in police work. Criminal Justice and Behavior, 27(3), 375-400.

Arbuckle J.L. (1997). AMOS users' guide version 4.0. Chicago: Smallwaters Corporation.

Brooks, L.W. \& Piquero, N.L. (1998). Police stress: Does department size matter? Policing: An International Journal of Police Strategies E Management, 21(4), 600-617.

Clark, L.A. \& Watson, D. (1995). Construct validity: Basic issues in objective scale development. Psychological Assessment, 7(3), 309-319

Cranny, C.J., Smith, P.C. \& Stone, E.F. (1992). Job satisfaction: How people feel about their jobs and how it affects their performance. New York: Macmillan.

Cropanzano, R. \& Wright, T.A. (2001). When a "happy" worker is really a "productive" worker: A review and further refinement of the happy-productive worker thesis. Consulting Psychology Journal: Practice and Research, 53(3), 182-199.

Daniels, K. (2000). Measures of five aspects of affective wellbeing at work. Human Relations, 53(2), 275-294.
Fairbrother, K. \& Warn, J. (2003). Workplace dimnsions, stress and job satisfaction. Journal of Managerial Psychology, 18(1), 8- 21.

Hirschfeld, R.R. (2000). Validity studies. Does revising the intrinsic and extrinsic subscales of the Minnesota Satisfaction Questionnaire Short Form make a difference? Educational Psychological Measurement, 60(2), 255-270.

Jackson, L.T.B., Rothmann, S. \& Van de Vijver, A.J.R. (2006). A model of work-related well-being for educators in South Africa. Stress and Health, 22(4), 263-274.

Kahn, R.L. \& Juster, F.T. (2002). Well-being: Concepts and measures. Journal of Social Issues, 58(4), 627-644.

Kline, P. (1994). An easy guide to factor analysis. London: Routledge.

Koortzen, P. (1996). Die dimensionaliteit van polisie-stressore. [The dimensionality of police stressors.] Acta Criminologica, 9(2), 55-63.

Lazarus, R.S. (1991). Psychological stress and the coping process. New York: McGraw-Hill.

Lazarus, R.S. \& Folkman, S. (1984). Stress, appraisal and coping. New York: Springer-Verlag.

Maslach, C., Jackson, S.E. \& Leiter, M. (1996). Maslach Burnout Inventory: Manual (3rd Ed.). Palo Alto: Consulting Psychologists Press.

Maslach, C., Schaufeli, W.B. \& Leiter, M.P. (2001). Job burnout. Annual Review of Psychology, 52, 397-422.

Mostert, K. \& Rothmann, S. (2006). Work-related well-being in the South African Police Service. Journal of Criminal Justice, 34(5), 479-491.

Myers, D.G. \& Diener, E. (1997). The new scientific pursuit of happiness. The Harvard Mental Health Letter, 4(2), 4-7.

Naudé, J.L.P. \& Rothmann, S. (2004). The validation of the Utrecht Work Engagement for emergency medical technicians in Gauteng. South African Journal of Economic and Management Sciences, 7(3), 473-487.

Nunnally, J.C. \& Bernstein, I.H. (1994). Psychometric theory (3rd Ed.). New York: McGraw-Hill.

Pienaar, J. \& Rothmann, S. (2003, September). Job stress in the South African Police Services. Paper presented at the 15th Conference of the South African Institute for Management Scientists, Potchefstroom.

Pienaar, J., Rothmann, S. \& Van de Vijver, A.J.R. (2007). Occupational stress, personality traits, coping strategies and suicide ideation in the South African Police Services. Criminal Justice and Behavior, 34(2), 246-258.

Ramirez, A.J., Graham, J., Richards, M.A., Cull, A. \& Gregory, W.M. (1996). Mental health of hospital consultants: The effects of stress and satisfaction at work. Lancet, 347, 724728

Rothmann, S. (2005, September). Work-related well-being in South African organisations: What do we know? Paper presented at the 7th Annual Conference of the Employee Assistance Professionals Association of South Africa, Durban.

Rothmann, S., Steyn, L.J. \& Mostert, K. (2005). Job stress, sense of coherence and work wellness in an electricity supply organisation. South African Journal of Business Management, 36(1), 1-9.

Rothmann, S. \& Strijdom, G. (2002). Suicide ideation in the South African Police Services in the North West Province. South African Journal of Industrial Psychology, 28(1), 44-48.

Schaufeli, W.B. (2003). Past performance and future perspectives of burnout research. South African Journal of Industrial Psychology, 29(4), 1-15.

Schaufeli, W.B. \& Bakker, A.B. (2004). Job demands, job resources, and their relationship with burnout and engagement: A multi-sample study. Journal of Organizational Behaviour, 25(3), 1-23.

Schaufeli, W.B. \& Enzmann, D. (1998). The burnout companion to study and practice: A critical analysis. London: Taylor \& Francis.

Schaufeli, W.B., Salanova, M., González-Romá, V. \& Bakker, A.B. (2002). The measurement of engagement and burnout: A 
confirmative analytic approach. Journal of Happiness Studies, $3(1), 71-92$.

Spielberger, C.D., Vagg, P.R., \& Wasala, C.F. (2003). Occupational stress: Job pressures and lack of support. In J.C. Quick \& L.E. Tetrick (Eds). Handbook of occupational health psychology. Washington, D.C.: American Psychological Association, pp. $185-200$.

SPSS Inc. (2006). SPSS 15.0 for Windows. Chicago, IL: SPSS Inc.

Storm, K. (2002). Burnout and engagement in the South African Police Services. Unpublished doctoral dissertation, Potchefstroom University for Christian Higher Education, Potchefstroom.

Storm, K. \& Rothmann, S. (2003). A psychometric analysis of the Utrecht Work Engagement Scale in the South African Police Service. South African Journal of Industrial Psychology, 29(4), 62-70.

Terry, D.J., Nielsen, M., \& Perchard, L. (1993). Effects of work stress on psychological well-being and job satisfaction: The stress-buffering role of social support. Australian Journal of Psychology, 45(3), 168-175.
Van Horn, J.E., Taris, T.W., Schaufeli, W.B. \& Schreurs, P.J.G. (2004). The structure of occupational well-being: A study among Dutch teachers. Journal of Occupational and Organizational Psychology, 77, 365-375.

Visser, M.R.M., Smets, E.M.A., Oort, F.J. \& deHaes, C.J.M. (2003). Stress, satisfaction and burnout among Dutch medical specialists. Canadian Medical Association Journal, 168, 271- 276.

Warr, P. (2002). The study of well-being, behaviour and attitudes. In P. Warr (Ed.). Psychology at work. London: Penguin Books, pp. 1-25.

Warr, P. (2007). Work, happiness, and unhappiness. Mahwah, NJ: Lawrence Erlbaum.

Weiss, D.J., Dawis, R.V., England, G.W. \& Lofquist, L.H. (1967). Manual for the Minnesota Satisfaction Questionnaire. Minneapolis: University of Minnesota.

Zedeck, S., Maslach, C., Mosier, K. \& Skitka, L. (1988). Affective response to work and quality of family life: Employee and spouse perspectives. Journal of Social Behavior and Personality, 3, 135-157. 